\title{
LEXICAL DENSITY IN READER'S DIGEST MAGAZINE
}

a Andara Ninggar Sari, ${ }^{b}$ Rosyida Ekawati

${ }^{a, b}$ Universitas Trunojoyo Madura

e-mail: andaraninggarr@gmail.com

\begin{abstract}
This study concerns with the use of lexical density in Reader's Digest Magazine. This study used quantitative method. In collecting data, the writer used the document method. The source of data of this research is the lexical items and grammatical items in Reader's Digest Magazine. In analyzing the data, the writer used lexical density theory by Ure. The source of data of this research is the lexical items and grammatical items in Reader's Digest Magazine. The result of the lexical density shows there are health article with density around $61,34 \%$, animal kingdom article with density around $61,56 \%$, languages article with density around $58,83 \%$, parenting article with density around 54, 68\%, and travel article with density around 64, 05\%.
\end{abstract}

Keywords: Lexical Density, lexical item, grammatical item, Reader's Digest 


\section{INTRODUCTION}

A magazine is a part of media communication that is developing rapidly from the first it exists until now. Before the global era came with all its sophistication, the magazine was one of the media to convey a message or news that was happening in the society. Even though the various information nowadays can be accessed easily through the internet or online, the existence of magazines constantly is found. One of them is Reader's Digest which still can survive with its loyal readers. Reader's Digest is a magazine that has English as a primary language existed in 1922 until now and it has been intended for all ages.Reader's Digest is a monthly magazine that contains a lot of information in the form of articles that are useful for the reader.

There are a lot of articles published in Reader's Digest magazine. They are developed to attract more readers because of the large amount of the information that they carry. One of them is health article. This section mostly tells about the information that related to the current issues, especially in the term of health. It relates to the reader's life because health and human cannot be separated.The existence of this article is intended for the additional information and knowledge in the term of health so that the readers can understand the current issues of health.

Another article is language. This article discusses about idioms and certain terms. Mostly, this part explains the words related to the idioms. In fact, the used of the word in the idiom has another meaning and it is more than literal meaning. In the term of idiom, the word that already conveyed by the speaker mostly has an expression that takes a figurative meaning. The idiom here is more playing words into a figure of speech that has a metaphor. Moreover, this article can be such an additional information about idiom language, so the readers will be more understanding about the idiom. Then another article is animal kingdom which tells all about animals. This article refers to the unique behavior of animals.

Parenting article is also available in the magazine. This article talks about the activity that the readers can do at home with their family, especially the positive activity. This article adds some new information about positive ways to spend the time with their lovely person. Furthermore, this is very useful information which can be applied at home. Moreover, the last article is travel. This article mostly talks about the beautiful place that can refresh the mind of the readers. This article served a lot of good pictures and good explanations regarding to the place. This article can be such information to the reader if they want to spend the time at some places that already wrote in the magazine.

In the form of magazine, the most components that readers can find in the articles is the text. Furthermore, the text of articles must contain of subject, verb, adjective, and others item that already affiliated with lexical items and grammatical items. In addition, some articles in other magazines have direct targets for adults, teens, and children, but the targets of the Reader's Digest magazine is known as general. So, it is hard to decide the articles that suit for the certain ages. Moreover, it is relatable with the lexical density and readability method that appropriate with this case.

Magazine can be said to be worth or not as the reading material for certain ages based on the result of calculating the lexical density. Lexical density is an idea to measure the density of a sentence. Lexical density is a way of counting the total number of words and then dividing them by lexical items. Lexical density is a method to measure the density of words contained in a sentence especially in reading material such as magazines. According to Halliday and Matthiessen (2004), "lexical density is a ratio where it is the content of words from a grammar or function of the word in a 
clause". To measure lexical density, it is important to differ between lexical items and grammatical items. Lexical items are also known as content of words that refer to verbs, nouns, adjectives, and some classes of adverbs. While grammatical words are included in items such as prepositions, pronouns, conjunction, auxiliary verbs, determiners, and articles. In spoken discourse, the content words tend to be wide spread over several clauses rather than being tightly packed into individual clauses which are more typical of written discourse.

Furthermore, according to Ure (1971), "lexical density as the number of lexical items, as the proportion of the number that is running in the words". He more refers to the use of lexical words rather than a non-lexical words. In the terms of lexical words and non-lexical words, Ure give the distinction between them. Lexical words refer to the use of the number of words where the words itself carry their own meaning. Then, non-lexical words refer to the use of the number of words that purely in terms of grammar.

A text with a high proportion of lexical items or content words, it has high information than a text with a high proportion of the function of words (prepositions, interjections, pronouns, conjunctions and count words). To find out the lexical density, counting the lexical items is needed. Furthermore, Ure (1971) stated that lexical density should be treated as the proportion for each number of lexical items in the words. Then, this formula is refined by Halliday (1985) as his first approximation to measure the lexical density and then become further developed by O'Loughlin (1995).

From the brief explanation above, this study will conduct lexical density in Reader's Digest especially on September 2019's edition,which is focused on health, language, animal kingdom, parenting, and travel articles. The topic of lexical density is chosen because the age range of the selected article in the Reader's Digest magazine is general and the classification of the age is unknown. Therefore, the study was conducted to reveal the level of lexical density for each article and category of the text.

\section{REASEARCH METHODS}

This study uses and applies the quantitative approach in order to understand the occurrences of lexical density in Reader's Digest magazine. the quantitative approach also considered the objective result by using numerical analysis.

Source of data on this study is the Reader's Digest magazine, the edition of September 2019. The specific articles are about health, language, animal kingdom, parenting, and travel. Furthermore, the data of this study is the lexical items in the form of words, phrases, and sentences that are found in the articles of health, language, animal kingdom, parenting, and travel.

Data collection was done by identifying the articles i.e. by underlining the lexical items and grammatical items with Free Claws Web Tagger and classifying the lexical items and grammatical items on each paragraph by using the table and tag set. After collecting the data, the analysis of the data was done by calculating the lexical items based on the paragraph by using the theory of Ure, counting the average of the resul, classifying based on lexical density measurement whether that is hard (60-70), standard (50-60), or easy (40-50). And the last is drawing the conclusion. 


\section{DISCUSSION}

The total of lexical items is based on verbs, adverbs, nouns, and adjectives. The data were obtained by using Free Claws Web Tagger application. There are 338 items of lexical for health article, 479 items of lexical for animal kingdom article, 323 items of lexical for language article, 590 items of lexical for parenting article, and 982 items of lexical for travel article. From the table above, it can be seen that the travel article has higher lexical items than the other articles that have chosen. Then, the article for animal kingdom has the lowest lexical items among other articles as shown in the following table 1 .

Table 1. The Classification and Total of Lexical Items in the Articles

\begin{tabular}{l|l|c|c|c|c|c}
\hline No. & \multicolumn{1}{|c|}{ Article } & Verbs & Nouns & Adjectives & Adverbs & $\begin{array}{c}\text { Total the } \\
\text { Lexical } \\
\text { Items }\end{array}$ \\
\hline 1. & Health article & 118 & 132 & 42 & 46 & 338 \\
\hline 2. & Animal Kingdom article & 153 & 204 & 64 & 58 & 479 \\
\hline 3. & Language article & 115 & 131 & 43 & 34 & 323 \\
\hline 4. & Parenting article & 235 & 210 & 59 & 86 & 590 \\
\hline 5. & Travel article & 234 & 475 & 152 & 121 & 982 \\
\hline
\end{tabular}

The types of article also can strongly affect the result of lexical density. Usually the most dominant types of the articles consist of the verb, noun, adjectives, adverb that include in the lexical items. Furthermore, the following table 2 shows the types of text for each article.

Table 2. The Types of Each Article

\begin{tabular}{l|l|l|c}
\hline No. & \multicolumn{1}{|c|}{ Article } & \multicolumn{1}{|c}{ Type } & Total the Lexical Items \\
\hline 1. & Health article & Explanation text & 338 \\
\hline 2. & Animal Kingdom article & Narrative text & 479 \\
\hline 3. & Language article & Narrative text & 323 \\
\hline 4. & Parenting article & Narrative text & 590 \\
\hline 5. & Travel article & Descriptive text & 982 \\
\hline
\end{tabular}

It is found that the text with high result of lexical items is travel article in the form of descriptive text. It was formed by noun, then followed by verb, adverb, then adjective. Besides, the text that has low result of lexical items was animal kingdom in narrative form that is composed by noun, then followed by verb, adverb, then adjective.

After finding the total of lexical items and the types, it is presented the calculation of lexical density. Calculation of the lexical density is important to reveal the total lexical items and total words according to the Ure's measurement. The total words here refer to the sum of all the texts that appear in the article. In addition, the result of the lexical density is summarized in the following table 3. 
Table 3. The Total of Lexical Density in the Articles

\begin{tabular}{l|l|c|c|c|c}
\hline No. & \multicolumn{1}{|c|}{ Article } & $\begin{array}{c}\text { Lexical } \\
\text { Items / } \\
\text { Content } \\
\text { Words }\end{array}$ & $\begin{array}{c}\text { Grammatical } \\
\text { items / } \\
\text { Function } \\
\text { Words }\end{array}$ & $\begin{array}{c}\text { Total } \\
\text { Words }\end{array}$ & $\begin{array}{c}\text { Lexical } \\
\text { Density } \\
(\%)\end{array}$ \\
\hline 1. & Health article & 338 & 213 & 551 & $61,34 \%$ \\
\hline 2. & Animal Kingdom article & 479 & 229 & 778 & $61,56 \%$ \\
\hline 3. & Language article & 323 & 226 & 549 & $58,83 \%$ \\
\hline 4. & Parenting article & 590 & 489 & 1079 & $54,68 \%$ \\
\hline 5. & Travel article & 982 & 551 & 1533 & $64,05 \%$ \\
\hline
\end{tabular}

The total of lexical density in the table 3 is the result of applying Ure's measurement. The total of grammatical items or function words in the table 3 above is to provide the detail about the result of grammatical items that this study already found. The existence of it cannot affect the result of lexical density, since the result of the lexical density is only needed the total of lexical items and words that exist in the article.

After calculating the lexical density, it is presented the level of lexical density based on Sholichatun's measurement. Applying the result of lexical density based on her measurement can show the article includes in the easy category, standard category, or difficult category.The usage of Sholichatun measurement might give the clue to the reader whether the article is appropriate to read or not. Furthermore, the following figure below provides evidence the level of lexical density according to Sholichatun's measurement.

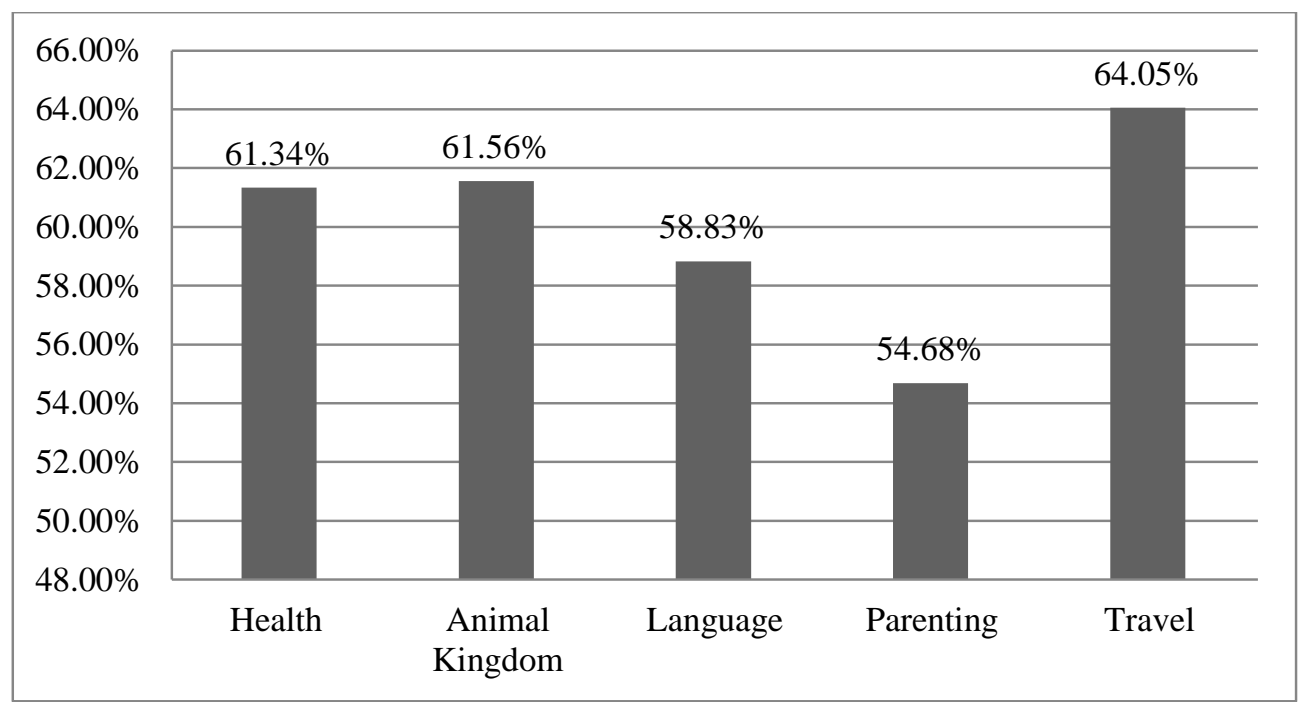

Figure 1. The Level of Lexical Density in the Articles

Sholichatun (2011) stated that the text is categorized as easy if the lexical density is around $40 \%-50 \%$. It is categorized into standard if the lexical density is around $50 \%-60 \%$ and the text is categorized as difficult if the lexical density is around $60 \%$ $-70 \%$. 
Table 4. The Level of Lexical Density in the Articles

\begin{tabular}{c|l|c|c|c}
\hline No. & \multicolumn{1}{|c|}{ Article } & $\begin{array}{c}\text { Easy } \\
(40 \%-50 \%)\end{array}$ & $\begin{array}{c}\text { Standard } \\
(50 \%-60 \%)\end{array}$ & $\begin{array}{c}\text { Difficult } \\
(60 \%-70 \%)\end{array}$ \\
\hline 1. & Health article & - & - & $\checkmark$ \\
\hline 2. & Animal Kingdom article & - & - & $\checkmark$ \\
\hline 3. & Language article & - & $\checkmark$ & - \\
\hline 4. & Parenting article & - & $\checkmark$ & - \\
\hline 5. & Travel article & - & - & $\checkmark$ \\
\hline
\end{tabular}

According to the figure 1 above, the result of lexical density in health article is $61,34 \%$ and this article is classified as difficult category. Then, the result of animal kingdom article is $61,56 \%$ and this article is also classified as difficult category. Another result comes from language article that generates the total around 58,83\% and is classified as standard category. Furthermore, the parenting article gives the result around 54,68\% and this article is classified as standard category. Moreover, the result of the travel article is $64,05 \%$ and this article is classified as difficult category. All the results of lexical density in the figure above is in accordance with Ure's measurement. Moreover, the following table 4 provides the level of each article, whether it is classified as easy category, standard category, or difficult category.

\section{CONCLUSION}

From the discussion, it can be concluded that there are three articles included in difficult category and two articles in standard category. The articles in the difficult category are Health article in the form of explanatory text, Animal Kingdom article in the form of narrative, and travel article in the form of descriptive text. Meanwhile, the articles in standard category are language article in narrative form and parenting article in narrative form. In addition, this study also reveals that the article that has the highest lexical density is travel article in the form of descriptive text. On the other hand, the article that has lowest lexical density is parenting article in the form of narrative text.

\section{REFERENCES}

Halliday, M. A. K. (1985). An Introduction to Functional Grammar. London: Cambridge. Edward Arnold.

Halliday, M. A. K., \&Matthiessen. (2004). An Introduction to Functional Grammar (3rd Eds.). London: Cambridge. Edward Arnold.

O'Loughlin, K. (1995). Lexical density in Candidate output on two versions of An oral Proficiency Test. Melbourne Papers in Language Teaching, 26-48.

Sholichatun, S. (2011). Content analysis of reading materials in English on sky textbook for junior high school. (A thesis). Retrieved on October 22, 2019, from http://eprints.walisongo.ac.id/1968/

Ure, J. (1971). Lexical density and register differentiation. In G. Perren and J.L.M. Trim (eds), Applications of Linguistics, London: Cambridge University Press. 443-452. 